\title{
CAMA
}

Centre for Applied Macroeconomic Analysis

\section{The Global Financial Crisis and the Language of Central Banking: Central Bank Guidance in Good Times and in Bad}

\section{CAMA Working Paper 58/2013 August 2013}

Pierre L. Siklos

Wilfrid Laurier University

Balsillie School of International Affairs and

Centre for Applied Macroeconomic Analysis (CAMA), ANU

\section{Abstract}

Words are critical in how the public perceives the work of central banks and the quality of monetary policy. Press releases that accompany policy rate decisions and, where available, the minutes of central bank committee meetings, are focal points for the media in public discussions about the conduct of monetary policy.

Using data from five countries, I examine whether the language used by central banks has changed since the global financial crisis (GFC) began.

Briefly, I find that concerns about financial stability peaked just as the global financial crisis reached its zenith. However, concerns over uncertainty about the current and anticipated state of the economy have also risen over time. More generally, central bank speak became more aggressive throughout the crisis years. More conventional expressions about the current stance of monetary policy took a back seat to other concerns in central bank policy statements and minutes. 


\section{Keywords}

central bank communication, financial stability, language analysis

JEL Classification

E52, E58, E61, E69

\section{Address for correspondence:}

(E) cama.admin@anu.edu.au

The Centre for Applied Macroeconomic Analysis in the Crawford School of Public Policy has been established to build strong links between professional macroeconomists. It provides a forum for quality macroeconomic research and discussion of policy issues between academia, government and the private sector.

The Crawford School of Public Policy is the Australian National University's public policy school, serving and influencing Australia, Asia and the Pacific through advanced policy research, graduate and executive education, and policy impact. 


\title{
The Global Financial Crisis and Central Bank Speak: CENTRAL BANK GUIDANCE IN GOOD TIMES AND IN BAD *
}

\author{
Pierre L. Siklos \\ WILFRID LAURIER UNIVERSITY, \\ BALSILLIE SCHOOL OF INTERNATIONAL AFFAIRS, \\ AND CAMA
}

\begin{abstract}
* Research for this paper was supported by a CIGI-INET grant. Samantha St. Amand provided superb research assistance. I am also grateful to Princeton University where I was a Visiting Scholar and where research for this paper first began, to the University of Otago for their hospitality while I was William Evans Fellow, and to the University of Tasmania where I was a Visiting Scholar. Previous version were presented at the the ASSA, the University of Wollongong, ANU, the University of Texas at Austin, the workshop "Recent developments in central bank transparency and communication", at RWTH Aachen, Germany, and the Asian Econometric Society Conference, Singapore. A version of this paper was prepare for the Handbook of DICTION Studies. Comments on earlier drafts by Jose Lopez, Shaun Vahey, and various conference participants, are also gratefully acknowledged.
\end{abstract}


The Global Financial Crisis and the Language of Central Banking:

Central Bank Guidance in Good Times and Bad

Pierre L. Siklos

Wilfrid Laurier University, the Balsillie School of International Affairs, and the Centre for Applied Macroeconomic Analysis

\begin{abstract}
Words are critical in how the public perceives the work of central banks and the quality of monetary policy. Press releases that accompany policy rate decisions and, where available, the minutes of central bank committee meetings, are focal points for the media in public discussions about the conduct of monetary policy.

Using data from five countries, I examine whether the language used by central banks has changed since the global financial crisis (GFC) began.

Briefly, I find that concerns about financial stability peaked just as the global financial crisis reached its zenith. However, concerns over uncertainty about the current and anticipated state of the economy have also risen over time. More generally, central bank speak became more aggressive throughout the crisis years. More conventional expressions about the current stance of monetary policy took a back seat to other concerns in central bank policy statements and minutes.

Keywords: central bank communication, financial stability, language analysis

JEL Classification codes: E52, E58, E61, E69

Pierre L. Siklos, WIlfrid Laurier University and Balsillie School of International Affairs, 67 Erb Street West, Waterloo, ON N2L 6C2, Canada.
\end{abstract}

Phone +1 2267723159 


\section{Introduction}

Until the financial crisis, followed soon after by the ongoing sovereign debt crisis in Europe, began to pre-occupy central banks central bank communication was dominated by an interest rate announcement. This was accompanied by a brief explanation of the outlook for the economy as well as a justification for the current stance of policy set by the monetary authority. To be sure, central banks communicated along many other dimensions. There were inflation or monetary policy reports and, increasingly, financial stability reports, among other publications produced by central banks aimed at both the well informed and general public.

The push towards greater transparency, and accountability, by central banks had its origins in an understanding between them and their governments that the monetary policy authority was both responsible for its actions and could be held to account for its decisions. In many, though not all, cases the agreement between central banks and governments consisted in giving the monetary authority full discretion over short-term monetary policy decisions. Longer term, and more strategic, decisions about the nature of the monetary policy regime (e.g., formal inflation targeting versus some alternative) would be left for the politicians, preferably in consultation with the monetary policy experts.

However, since at least 2008, monetary policy actions shifted away from interest rate changes to other types of announcements. As shown in Figure 1, three developments, in particular, characterize the dramatically changed role of the central bank policy rate since the onset of the global financial crisis. First, interest rates fell quickly as central banks, seemingly slow at first to recognize the severity of the financial shock, eventually responded by loosening the stance of monetary policy on a scale rarely seen in recent decades. Second, particularly in the economies most directly affected by the crises (i.e., the US, the UK, and the euro zone), policy rates effectively reached the so-called zero lower bound, that is, a threshold that could not be breached since 'negative' interest rates, even if feasible, are often deemed impractical. Finally, policy rates have remained at, or near their lowest levels, for at least three years, if not 
longer, and, as this is written, there are few signs that central banks will raise policy rates anytime soon.

In this kind of environment, the central banks most affected had few options but to devise new instruments to help their economies recover as well as, arguably, relying more heavily on their policy statements to influence expectations of financial markets and the general public. The new monetary policy tools referred to as 'unconventional', together with greater reliance on verbal aspects of central banks actions, arguably complicated the communications strategy of central banks.

This paper considers whether one can detect a change in the language that five central banks have used to communicate their actions and elements of their outlook since the events of 2008. The environment of historically low interest rates, the introduction of a panoply of actions that served to loosen monetary policy even when the zero lower bound was reached, as well as fending off criticisms from both politicians and the public about whether their policies would stoke future inflation, if not a renewed financial crisis, might be expected to conspire to create a change in the tone of central bank verbal communications. Of course, this assumes that the shock of a financial crisis on a global scale would influence how central banks communicate their actions to the public. Yet, a case can also be made that, to avoid the appearance of panic or an inability to comprehend the seriousness of the situation, as well as convey competence and an aggressive response to the severe economic shock affecting the major advanced economies, central banks may well have chosen to follow a 'steady as she goes' approach in their communications practices. Such a view might be taken as consistent with a more strategic view of central bank behavior wherein the central bank prefers not to fully divulge the underlying truth about the state of the economy as a device to influence expectations in the direction of ending crisis conditions that may pervade thinking, say, in financial markets.

Finally, while the crises had a global dimension it needs to be underscored that not all faced the predicament that afflicted, say, the US Federal Reserve or the Bank of England. Several central banks in the industrial world did not engage in unconventional 
monetary policies nor were unorthodox interventions necessary. Examples include the Reserve Bank of Australia, the Bank of Canada, and the Reserve Bank of New Zealand. Moreover, not all central banks face the same zero lower bound restriction on policy interest rates that currently constrain interest rate actions by the Federal Reserve or the Bank of England. Hence, the 'verbal' instrument in monetary policy might well have taken on a more prominent role in economies subject to the crises the world has endured since 2008.

The rest of the paper is organized as follows. The next section provides some background concerning the role and functions of central bank communication as well as some illustrations of the principal means used to convey monetary policy actions and the stance of policy. Next, the data are described and some stylized facts are presented. The DICTION software is used to generate indicators of changes in the language used by central banks before and since the crisis erupted in 2008. Finally, some simple econometric evidence is presented to examine whether a change in emphasis in monetary policy announcements can be statistically related to a set of macroeconomic determinants. The paper concludes with a brief discussion of the implications from the empirical analysis.

\section{Central Bank Communication Tactics}

Over the years there have been steady improvements in the amount and type of information disclosed by central banks. As noted in the introduction this was, in part, a natural outcome of the autonomy given to central banks as well as a clearer understanding of where accountability for monetary policy decisions lies.

The U.S. experience, for example, is one that is mirrored elsewhere and serves as an illustration of developments that spread around the world since the 1990s. First, central banks began to announce their policy rate decisions immediately, or very soon after, a decision was taken. In the Fed's case this took place in 1994. In 1997, the Fed began to provide a numeric value for the 'intended' fed funds rate, the policy rate set by the Federal Open Market Committee (FOMC). By 1999 the Fed began to announce, at 
the time of the press release announcing its policy decision, a 'bias' to provide some guidance for markets and the public about the direction in which the stance of monetary policy was leaning. In 2000 , the 'bias' in the policy statement was replaced with an expression of the 'balance of risks'.

More explicit reforms aimed at providing forward guidance about monetary policy actions were spurred, first, by the aftermath of the bursting of the 'tech bubble' when, in 2003, expressions indicating 'accommodation [in monetary policy] for a considerable period' began to appear in the FOMC's press releases. This would be followed later, at the height of the 'global' financial crisis, by statements indicating that the fed funds rate would remain 'exceptionally low for an extended period' of time'. In addition to the various policy actions taken since 1999 to restore the health of the U.S. financial system, and the economy more generally, called quantitative and credit easing policies, the Fed announced a medium-term inflation objective in 2012, followed by improvements in how the Fed portrays the views of FOMC members about their outlook for inflation and economic growth as well as indications about when the fed funds rate might escape from its current zero lower bound. At the beginning of 2012 the Fed announced a longer-run goal of $2 \%$ inflation. Finally, at the end of 2012, the Fed explicitly began to indicate that it would respond to unemployment rate levels, among other economic indicators, before deciding when to exit from the current extraordinary macroeconomic environment.

Changes in the manner in which central banks communicate and the language used was not necessarily as dramatic elsewhere. In some countries (e.g., Australia, Canada, and New Zealand) policy makers stuck with their policy of 'flexible' inflation targeting while seemingly not encountering the same economic effects of the financial crisis as in the U.S.. Others, such as the Bank of England, faced the twin crises of financial system instability and inflation rates that regularly exceeded the mandated target. The response to the first crisis was to introduce quantitative easing (QE), that is, measures to further loosen monetary policy when policy rates were near or at the zero lower bound, while the second required the publication of letters, on a regular basis to the Chancellor of the 
Exchequer (Britain's Finance Minster) explaining why the inflation target was missed and providing assurances that the agreed upon goal for inflation would eventually be met.

Not surprisingly, research into the benefits, costs, and consequences of central bank communication has spawned a new literature that continues to grow over time. Policy makers themselves came to see communication as having practically the same importance as the policy rate decisions made by central banks. As Bini Smaghi (2007), a former member of the Executive Board of the European Central Bank (ECB), noted: “...central bank communication can be as important and effective as the traditional instrument of policy, i.e. the interest rate."

Words, however, as opposed to actions (e.g., a change, or not, in the policy rate) creates at least two sets of challenges. First, communication needs to be clear to be properly understood. Second, to be effective, communication must support and convince markets and the public about the central bank's thinking. It should only 'surprise' markets when expectations, at least in the minds of the policy makers, are seriously misaligned with prices and other indicators in financial markets and the economy more generally. Not only are these challenges difficult to meet but, in the mere two decades since central bank communication became a critical part of central banks' monetary policy strategy, there has understandably been, and continues to be, a considerable amount of experimentation, a point recently underscored by Yellen (2012), Vice-Chair of the FOMC.

In the realm of economic research on the role and influence of central bank communication two different strategies have been followed. Some authors (e.g., Dale et.al. 2011) ask whether the impact of central bank communication is determined by the ability of the public to assess the 'quality' of signals emanating from the monetary authority. Clearly, this will be a function not only of clarity but potentially the quantity of information provided. Therefore, a central bank ought to be concerned about how precisely it communicates lest too much communication becomes detrimental in welfare 
terms. ${ }^{1}$ In other words, central bank communication needs a strategy much like the adoption of a particular monetary policy must be thought through in strategic terms.

Results, such as the ones described above, are obtained from stylized economic models rather than relying on examples or empirical evidence. Other results in this vein rely on micro-founded models, with or without, rational expectations and these too suggest that information accuracy is a critical element in successful central bank communication because it offers the best way to align the public's expectations with the actual monetary policy strategy being implemented (e.g., see Eusepi and Preston 2010). Therefore, a mere declaration that the central bank will, henceforth, target inflation is not enough to prevent monetary policy from being de-stabilized. It should be noted, however, that many such models omit a financial sector and offer no guidance about how best to combine the various strands of central bank communication activities.

A separate strand of research is empirical in nature and consists in quantifying in a number of ways not only what central banks say (e.g., in press conferences) and write (i.e., policy statements, Reports of various kinds) but also how the media respond to central banks attempts to explain themselves. A few examples serve to illustrate this kind of research. For example, Bulír et.al. (2012) are interested in the clarity of central bank communication which is assumed to be a function of the economic environment. The more uncertain the outlook the more difficult it is to clearly communicate, it is claimed. If the hypothesis seems plausible it is far from obvious why overall economic uncertainty should made clarity more difficult. First, central bank communication is not exogenous. Central banks, as the U.S. experience for example clearly illustrates, adjust their thinking about communication when the underlying economic environment changes. This could well be an attempt to ensure that clarity is maintained. Second, clarity is about the content of the message and there is no reason why this should be

\footnotetext{
${ }^{1}$ Morris and Shin (2002) outline a theoretical model where a transparent and credible central bank prompts the public to ignore any adverse economic signals that might lead it to disagree with, say, a central bank forecast. As a result, the central bank and the public coordinate their outlook for the economy with the implication that the latter become complacent about using and interpreting potentially valuable information.
} 
held constant as the economic outlook becomes more uncertain. In any event, the authors conclude, based on data from Chile, the U.K., the Czech Republic, the ECB, Poland and Sweden, that clarity does not suffer when the outlook becomes more uncertain. However, they also report that the level of understanding required to interpret central bank communications has increased since the onset of the global financial crisis. $^{2}$

Next, a series of papers attempt to interpret the textual material produced in several forms by central banks, code the results, usually in the form of a dummy variable that may or may not be ordered, to ask whether markets are moved by these attempts by central banks to communicate. Excellent examples of this kind of research include Ehrmann and Fratzscher (2007, 2009), and Berger, Ehrmann and Fratzscher (2010). Essentially, the aim is to ask how a perceived tightening or loosening of policies, as interpreted either by the central bank or certain media outlets, might affect, say, selected asset prices (e.g., stock returns, market interest rates).

For the major central banks (e.g., the ECB and the Fed) the overall evidence points in the direction of both improvements and greater effectiveness in central bank communication in recent years. To be sure there are differences according to whether monetary policy decisions are carried out in a collegial or individualistic manner. For example, the Fed's FOMC members individually communicate their own views while policy decisions tend to be made in a more collegial atmosphere. The reverse seems to be true at the Bank of England where members of the Monetary Policy Committee are individually accountable for their actions. With very few exceptions, however (see Bligh and Hess (2013), and e.g., Born, Ehrmann, and Fratzscher (2013), and some sources therein), content analysis of the kind developed by DICTION is not used. Instead, an

\footnotetext{
${ }^{2}$ In a similar vein Demers and $\mathrm{Yu}$ (2013, in this volume) consider whether there is a link between confidence or ambiguity of the language used to convey earnings forecasts and forecasting performance. Forecasting performance appears to be reflected, for example, in the level of uncertainty expressed in the precision of earnings forecasts. Ongoing research explores the parallel phenomenon concerning the record of central bank forecasts, notably of inflation, the confidence with which such performance is expressed by the central bank and the impact on private sector and other types of forecasts.
} 
automated procedure, possibly combined with researchers' interpretation, serves as the basis for quantifying central bank or media releases. Tudor and Vega (2013, in this volume) review a small sample of papers that create quantitative indicators based on qualitative data and report that, while extremely useful, there remain several problems that need addressing. First, the appropriateness of the dictionaries used to create content type indices is an important question since Loughran and McDonald (2011) demonstrate that some words that may have a negative connotation in one context may be neutral in others. Moreover, where as some words that might evoke positive or negative sentiment is a general context are included in standard dictionaries used in content analyses more recently used terms that have proved important might well be left out as they are uncommon. Arguably, however, a crisis can bring out the usage of new terminology to describe a particular stance or situation.

The bottom line to date, in so far as central bank communication is concerned, has produced a consensus of sorts. First, improved predictability in policy has served to raise the effectiveness of monetary policy. Nevertheless, there are a number of potential pitfalls in how much, how frequently, and what information central banks communicate to the public. In particular, when it comes to forward guidance, it appears to be important for the central bank to explain the contingencies of any commitments made about the future stance of policy (e.g., Woodford 2005). This seems to be a lesson that the Fed, as well as other central banks, have tried to take to heart.

More generally, however, research on central bank communication is at a sufficiently early stage so that there remain many issues for future work (e.g., see Blinder et al. 2008). For example, the issue of 'best practice' in central bank communication is largely an unsettled question. The matter is further complicated by the adoption of new central bank instruments and the rise in the number of functions and responsibilities handed over to them in the aftermath of the ongoing crises (e.g., see Born et.al. 2010, Siklos 2012). In addition, there are a wide variety of effects from central bank pronouncements on financial markets. Finally, we are still a long way from understanding how central bank communication can anchor expectations and we are unsure about the role played 
by institutional considerations in determining how and when central bank communication can be effective.

\section{Data and Econometric Specification}

\subsection{Data and Some Stylized Facts}

In what follows I investigate econometrically, at the quarterly frequency, the information content of press releases that accompany a monetary policy decision, using DICTION, version 6.0. The sample considered is 2003-2012 and five English speaking central banks are examined. Stylized facts, however, are presented at the monthly frequency. ${ }^{3}$ They are: Australia, Canada, New Zealand, the U.K., and the U.S.. ${ }^{4}$ In addition, three of these countries' central banks, namely, Australia, the U.K., and the U.S., publish the minutes of monetary policy committee meetings. We consider these as well not only because minutes possibly offer deeper insights into the thinking of the individual members of the policy making committee, while the press release is a consensus style document. Moreover, the length of the minutes provides additional material that could be helpful in delineating how central bank communication may have changed over time and between types of published statements. It should be noted that members of the policy committees of central banks where minutes are published are aware that their thinking will be made public although the comments are not always attributed to individuals. Hence, it is likely that the choice of words will play a critical role in what is published. ${ }^{5}$

\footnotetext{
${ }^{3}$ Wherever possible the data were originally collected at the monthly frequency. In part because not all central banks meet on a monthly basis (e.g., the Bank of Canada and the Federal Reserve) it was more convenient to convert all monthly data to quarterly data via simple averaging of monthly values when conducting the econometric analysis.

${ }^{4}$ The regular release of a press release to accompany a monetary policy decision is a relatively recent occurrence and explains the choice of 2003 as the start of the sample.

${ }^{5}$ All of the central banks considered in this study, save the Fed (at least until 2012), have a numeric inflation target they are committed to. For a variety of reasons, including the difficulty in distinguishing inflation from non-inflation targeting central banks, at least in how monetary policy is actually conducted, no explicit distinction along this dimension is made across the central banks considered.
} 
The contents of press releases and minutes are analyzed according to whether they contain words that convey information about the central bank's concern about the 'stance' of monetary policy, the state of 'financial stability', the level of 'uncertainty' the central bank is admitting to facing about the economic outlook, as well as an indicator of how 'strong' (i.e., aggressive) its monetary policy actions are. The latter are constructed as a sub-set of the indicator of uncertainty. Additional words were added to the dictionary both to ensure that content is adequately measured as well as in recognition that not all aspects of central bank 'speak' may be captured by the DICTION dictionaries. Examples of words that convey the stance of monetary policy are: accommodative, easing, or tightening; for financial stability the relevant words include credit, financial, liquidity, quantitative, unorthodox, stability; uncertainty is conveyed by words such as: crisis, exceptional, headwinds, imbalances, recession (or depression), risk, sluggish, and stress. Turning to strong language, words that are consistent with this sentiment include: crisis, exceptional, recession (or depression), and stress.

It is fairly straightforward to provide some illustrations linking central bank statements and the keywords used to classify them in the manner just described. For example, on 6 November 2008, the Bank of England (BoE) lowered its policy rate from $4.5 \%$ to $3 \%$, which constitutes a very large reduction in this kind of interest rate. In the press release that accompanied the statement the BoE points out that their action was in part justified because "...money and credit conditions have tightened considerably." On February 5, 2013 the Reserve Bank of Australia (RBA) did not change its policy rate but goes on to point out in the press release explaining the decision that "[D]uring 2012, there was a significant easing in monetary policy....an accommodative policy is appropriate." Both statements pertain to an evaluation of the stance of monetary policy. The following two statements from the Bank of Canada (BoC) refer to words associated with uncertainty. In both cases the policy rate did not change. On June 4, 2009 the BoC stated that "The outlook is subject to considerable uncertainty." In January 2013, the BoC's statement suggests that "...global tail risks have diminished." Turning to wording

\footnotetext{
${ }^{6}$ The words in italics are key words used to create subsequent scores.
} 
that relates to financial stability is an example from statements released by the FOMC of the U.S. Federal Reserve (FED). The policy rate was reduced by 50 basis points. The statement, announcing a reduction of the fed funds rate from $3.5 \%$ to $3 \%$, on September 18, 2009, argues that "[F]inancial markets remain under considerable stress." Finally, to capture words that indicate a strong or aggressive response to the underlying economic environment consider the following statement made by the Reserve Bank of New Zealand (RBNZ) on 29 January 2009, announcing a 150 basis point reduction in the policy rate from $5 \%$ to $3.5 \%$ : "The global economy is now in recession and the outlook for international growth has been marked down considerably."

Figure 2 plots the word count of press releases for each of the five central banks considered in this study while Figure 3 repeats the exercise for the three central banks, namely the RBA, the BoE, and the FED, which release minutes of their policy meetings, with a lag that varies but which has become shorter over time. The RBNZ and the BoC do not release minutes as their respective Governors are the sole decision-makers. Nevertheless, the Governors at these central banks do consult with other senior officials in their institutions (e.g., with Deputy-Governors).

The number of words that accompany RBA policy rate decisions has grown steadily over time since 2003. The plot reflects the fact that, until 2008, statements did not accompany all interest rate decisions. Similarly, the word count of policy statements of the Bank of Canada has also risen over time although there are clear in-year variations. Notice that the word count that accompany decisions by the Monetary Policy Committee of the BoE is similar to that of the RBNZ the total word count of press releases by the other central banks shown is almost twice as large. Also notable, in the case of the BoE, is that the word count tends to rise when the BoE announces not only an interest rate decision but, since 2008, when a decision about a change in the degree of quantitative easing (QE) is also announced. The relevant cases are indicated by the vertical dashed lines. Similarly, the Figure also identifies specific episodes when the length of statement that a central bank issues might be influenced by an additional announcement of some 
kind. For example, between April 2009 and April 2010, the BoC made a conditional commitment to hold rates at their zero lower bound (see Figure 1) for one year.

Figure 3 displays the word count for the minutes of policy making committees. Interestingly, and with few exceptions, their length is comparable across the three central banks, in spite of differences in size and structure of the various policy-making bodies. The apparent spike in the word content of FED minutes in January reflects the fact that, at the beginning of each calendar year, the FOMC must make a number of authorizations (e.g., open market operations, foreign exchange transactions). Moreover, the January FOMC meeting was scheduled over two days (as is true of the June meeting) and, until recently, the remainder of scheduled FOMC meetings were typically one day long. ${ }^{7}$ Another distinguishing characteristic of the recent U.S. experience is the number of 'unscheduled' meetings. Over the 2003-2012 period there were 13 such unscheduled meetings. The minutes of these meeting are typically appended to those of the next regularly scheduled FOMC meeting.

It could be argued that the policy rate decision and the accompanying statement are complements, not substitutes. This is clearly true in some cases. However, as shown in Figure 1, policy rates have been at historic lows for years, if not at their zero lower bound, for years. Hence, it is likely that the content of such press releases have taken on an importance on their own as a critical signal of the near term direction of monetary policy. As shown in Figure 4, there is no obvious connection between the size of changes in central bank policy rates and the content of press releases, as measured by word count. As pointed out above, this has happened in spite of the fact that press releases have grown somewhat longer over time. The most dramatic illustration is, again, the FED's experience. The FED, like the BoE, sharply reduced the policy rate as the financial crisis gathered pace. The working hypothesis is that, while central bankers chose to respond to the extraordinary events since 2008, in part by explaining at greater length what they were doing and why, they may well have also chosen to focus on the

\footnotetext{
${ }^{7}$ I am grateful to Bob Hetzel of the Richmond Fed for clarifying some of the issues around the content of FOMC meetings and the preparation of the minutes.
} 
content of the statement published after a monetary policy decision. Obviously, this is an empirical question.

Hence, in Figures 5 and 6 indicators of the content of policy statements and minutes are shown for each central bank examined in this study. To conserve space the data for all central banks are shown together. The height of each portion of the bar charts gives an indication of the relative importance of the content of press releases or minutes I have chosen to examine. ${ }^{8}$

If we are only interested in the relative importance of each indicator then it is clear that content dealing with financial stability dwarfs other concerns central banks were willing to make public. It is equally notable that this result holds both for the policy statements and policy meeting minutes. To the extent that the latter is a reflection of the policy making bodies true concerns about the state of the economy and their future outlook then policy statements fairly reflect the committee's opinions. Of course, a slightly more cynical view would recognize that members of the policy making body, aware that the minutes will be published in some form, are careful to choose what they say and how to express their opinion in the policy making committee. An additional filter not considered here, and one that could not be implemented in all cases where minutes are published, would be to consider the individual committee members' statements in the minutes. This extension is left for future research.

A fairly close second concern of the central banks in our study is uncertainty. This too is not surprising, especially in light of the events of the past five years. Nevertheless, content that pertains to uncertainty is not as consistently expressed in the policy statements as it appears to be the case in the minutes. Hence, there may well be substantive differences in the information conveyed in the minutes relative to those that appear in the press release that accompanies each policy rate decision. Similarly, there seem to be persistent differences as between policy statements and minutes when it comes to conveying the accommodative stance of monetary policy. Moreover, it is

\footnotetext{
${ }^{8}$ For readers wanting to see versions of Figures 5 and 6 for each of the central banks considered in this study these are available in an unpublished appendix.
} 
interesting to note that, in most cases, the content of policy statements that relate to policy easing in some form peaks at the height of the financial crisis and then tends to either decline or disappear altogether, presumably in favor of signaling some of the other concerns of policy makers.

Since the press release issued by a central bank may be likened to a consensus view of the members of policy making body it is interesting to ask, in very general terms, to what extent is sentiment in the minutes reflected in the press releases. One way to address this question is to examine the simple correlation coefficient between these two documents, at least for the three central banks in our study where minutes are available. Similarly, one might expect some of the particular word choices focused on in the period under investigation to be more likely to appear in the same document. In other words, ne might expect that concerns over economic uncertainty and, say, financial stability are likely to appear more frequently together than in a random manner. Moreover, it may be of interest to determine whether these types of correlations are sensitive according to whether the economy in question was in crisis or not. In selecting the crisis dates I follow the dating chronology of Dominguez, Hashimoto, and Ito (2012).

Table 1A presents the relevant correlations. In the case of the FED's press releases all four types of sentiment variables (i.e., stance, financial stability, uncertainty, and strong) are significantly correlated with each other as between press releases and the FOMC's published minutes. Only financial stability and the stance of monetary policy in the press releases and the minutes of the RBA are correlated while financial stability and the aggressiveness with which statements convey current monetary policy actions are correlated in the case of the BoE.

Turning to the press releases only, the only significant term, before and during the crisis in all five central banks examined, that is correlated with all the other expressions of sentiment is uncertainty. Financial stability and uncertainty are correlated in the case of the FED and the BoE but the correlations largely vanish in the other central banks considered. Of course, the financial crisis directly affected both of these central banks to a greater extent than the others examined here. Finally, once the crisis is underway, the 
correlation between the stance of monetary policy and any of the other sentiments that might be associated with the crisis disappears entirely as none of the correlations shown are statistically significant.

Of course, a natural criticism of the correlations is that the dating of the crisis was given and the data were not allowed to speak for themselves. Therefore, table 1B asks: to the extent that central banks consistently use similar terms over time to convey their views about monetary policy what would a simple test of a break in such a relationship find? To answer this question I estimated an autoregressive model of order one (i.e., AR(1)) and applied the Quandt-Goldfeld breakpoint test. ${ }^{9}$ The estimated specification can be written as follows

$$
C_{t}^{i}=\rho_{0}+\rho_{1} C_{t-1}^{i}+U_{t}
$$

where $C^{\prime}$ is the content indicator, with $i=1,4$, to indicate that four separate indicators, previously defined, are considered. As expected only the FED and the BoE's statements show any signs of a structural break in the above relationship and, in almost every case, the break takes place during the period of the financial crisis.

\subsection{Econometric Analysis}

In what follows I consider a very simple specification, namely

$$
C_{t}^{i}=\alpha_{0}+\alpha_{1} Z_{t}+\varepsilon_{t}
$$

where $C^{\prime}$ was defined above. The vector $\mathbf{Z}$ indicates the economic or institutional variables that are hypothesized to determine the content of policy statements and minutes. These include the following: a measure of the output gap, the inflation gap, the size of the accompanying change in the policy rate, a measure of the return on equities, a widely used measure of economic uncertainty, namely the VIX, and a real exchange rate indicator. For the small open economies in our data set, that is, Australia, Canada, and New Zealand, we also consider a commodity price indicator. Finally, some

\footnotetext{
${ }^{9}$ Essentially, the test procedure involves applying a conventional Chow breakpoint test at every observation between two dates.
} 
institutional determinants are permitted to separately influence the content variable. Thus, in the BoE's case, we consider the impact of the policy of quantitative easing (QE). In the case of the FED, we consider the role played by unscheduled meetings of the FOMC. Finally, in the BoC's case, we consider the period of the conditional commitment (April 2009-April 2010). All of these institutional variables are introduced as dummy variables, set to 1 when an event takes place (e.g., an increase in QE, or an unscheduled policy meeting) and zero otherwise.

A number of assumptions have to be made to justify a specification such as equation (1). First, since the specification is estimated separately for each content indicator these are effectively assumed to be independent of each other. There is no reason why this has to be the case though the evidence presented in Table $1 \mathrm{~A}$, at least for the press releases, suggests few difficulties stem from this assumption. Nevertheless, owing to the relatively short samples considered, we eschew these complications which are left for future research.

A second assumption of the proposed specification is that the right hand side determinants of content are exogenous. While it is reasonable for the content of central bank policy statements and the minutes of the policy making body to respond to the state of the economy and the other determinants described above, it is also worth considering the possibility that content is fashioned in such a way as to minimize the economic impact of any central bank announcement. After all, central bankers have repeatedly underscored their determination to inform and not 'surprise' markets. Therefore, there is an element of endogeneity in some of the right hand side variables in (1). Extension to the case where the extent of the endogeneity is tested and corrected, where necessary, is also left for future research.

Finally, since the length of policy statements and minutes is finite, and the content indicators previously defined are also limited to between 0 and 1 , the latter indicating that $100 \%$ of the content of the particular document being analyzed is associated with the particular indicator considered, it is natural, when estimating (1), to view the 
dependent variable as being censored on the left (i.e., to zero or $0 \%$ ) and on the right (to 1 or $100 \%$ ). Therefore, equation (1) is estimated via Tobit. ${ }^{10}$

Taken together then the results presented in the following section should be viewed as illustrative rather than definitive.

\section{Empirical Results}

Table 2 provides the main results of interest. Only the results when $C_{t}^{i}$ is proxied by the policy statements are displayed. The same right hand side variables are used for each content indicator considered. If a particular variable is not included it was found to be highly statistically insignificant in a previous round of estimation.

First, all content indicators respond to key macroeconomic variables of interest. This suggests that, during the period investigated, policy statements convey the concern the various monetary authorities expressed over financial stability, uncertainty, the stance of monetary policy and the aggressiveness of central bank language used in press releases. Clearly, since the period being investigated is dominated by the twin crises that originated in the U.S. and the euro zone this is not be surprising. ${ }^{11}$ Nevertheless, the results do point to the usefulness of content analysis as a way of highlighting the role of words, and not only actions, in the conduct of monetary policy.

Next, it is interesting to see that changes in the policy rate have relatively little effect on most of the content indicators. Nevertheless, when central banks take action, such as reducing the policy rate - the usual outcome during the sample considered - this is always an indicator of rising uncertainty about the future outlook, or heightened concern over financial stability questions. Only in the case of the RBA and the RBNZ does a rise

\footnotetext{
${ }^{10}$ Alternatively, we could set the content indicator to zero or 1 depending upon whether the relevant terms are contained in the policy statement or minutes. In this case we effectively ask: what is the probability that any of these documents have the content we are interested in? A logit specification would be suitable under the circumstances. Some estimates along these lines were generated but they generally support the conclusions summarized below and are not shown to conserve space.

${ }^{11}$ Roughly $60 \%$ of the sample can be said to be dominated by crisis related actions.
} 
in the policy rate signal a less accommodative stance, or vice-versa. Notwithstanding the peculiarities of the era under investigation the results do tend to point in the direction of policy rate changes complementing the content of policy statements where these were found to be statistically significant. In other words, actions may speak louder than words but, for the most part, the central banks in our sample also use the opportunity of the press release to underscore the reasons for a change in the policy rate.

Financial stability can be measured in a number of ways. While the content of policy statements can evoke something about the monetary authority's position on the subject, financial markets have also developed indicators of financial system stability, financial conditions indicators, or indicators of financial stress. In the latter case the VIX is a widely used indicator of volatility in stock markets. Yet, there a few indications from Table 2 that changes in the VIX have an impact on the content of central bank press releases. Only for Canada is a higher VIX associated with greater concerns over the state of uncertainty while a higher VIX translates, somewhat counter-intuitively, to fewer concerns raised about financial stability.

Turning to the variables that define the standard instrument rule used by central banks, at least until the financial crisis drove some of them to reduce policy rates to the zero lower bound, it is found that both the output gap and the inflation gap influence most the content of policy statements that reflect the central banks views about the stance of monetary policy. ${ }^{12}$ Moreover, on balance, the output gap figures less prominently than the inflation gap as a variable that influences the content of central bank press releases. Notice, however, there is some heterogeneity in the results. For example, while a higher inflation gap is associated with a more accommodative stance in the BoE's case the opposite is true at the RBA. Recall that the Governor of the BoE issued several letters indicating that the central bank would miss its inflation target while softening the stance of policy as a result of the financial crisis. The RBA, however, did not experience either a financial crisis or a recession during the period examined so

\footnotetext{
${ }^{12}$ Recall, the output or inflation gap is the difference between observed and trend values of the logarithm of real GDP or the price level.
} 
monetary policy acted as it normally would. Indeed, the RBA is one of the few central banks in the industrial world that raised policy rates.

Turning to the output gap this variable seems to have the most impact on the stance of monetary policy, as expected. After all, the ubiquitous Taylor rule relates the inflation and output gaps directly to the stance of monetary policy. Nevertheless, here too there are cross-country differences. For example, while a negative output gap (i.e., output below trend) signals a looser stance in policy, at least as conveyed in the words of press releases from the FED and the RBNZ, monetary policy is seen as tightening somewhat at the $\mathrm{BoC}$ and the BoE. Since the data used to generate estimates of the output gap in this study were revised it is conceivable that relying on the actual data that central banks had at their disposal might lead to different results. Alternatively, taken at face value, the behavior of the $\mathrm{BoC}$ and the $\mathrm{BoE}$ goes against the principles of the Taylor rule view of how policy rates should be set.

Finally, it is clear that the episodes of quantitative easing by the BoE and the period of the conditional commitment at the BoC impact content about financial stability. Indeed, in both cases, the events in question point to these two central banks expressing greater concerns over financial system stability. At the same time, however, QE and the BoC's conditional commitment policy are associated with less content dealing with economic uncertainty. Hence, it is possible that these policies were able to focus attention on certain challenges facing central banks as reflected in the contents of some of their public statements. Clearly, a policy meant to convey less uncertainty may naturally raise concerns over the state of financial system stability. In addition, in the case of the $\mathrm{BoC}$, the period of the conditional commitment signals stronger language about the direction of monetary policy while, at the BoE, QE results in the content of its press releases relying on less aggressive language. In the BoC's case the strong language could be viewed as reflecting the BoC's desire to return inflation to target during a spell or low to negative inflation. In the BoE's case QE was intended to convey a signal of more aggressive monetary easing, an example of actions being stronger than words. This seems to corroborate the view that actions, combined with strong 
language conveying the central bank's views about policy actions being taken, complement each other.

\section{Conclusions}

This paper has examined whether the language used by five central banks has changed since 2003 to reflect, among other questions being considered, more concern about financial stability and uncertainty about the economic outlook. The paper also considers the extent to which central banks signal the stance of monetary policy as well as how strong is the language used in communicating with markets and the public. The sample considered is from 2003 to 2012 and policy statements and minutes, where available, of central bank policy committees are considered. The five central banks examined are: the Reserve Bank of Australia, the Bank of Canada, the Reserve Bank of New Zealand, the Bank of England and the U.S. Federal Reserve.

I find that central banks in all the countries considered began to display much greater awareness or concern about the need to convey a message about the state of financial system stability as well as signal about the level of uncertainty about the economic outlook in their respective economies. Relatively less effort is devoted, however, to communicating the stance of monetary policy or in the aggressiveness in the wording about economic conditions in policy statements. A simple specification is then used to determine whether there exists a statistical connection between the content of central bank statement and a series of macroeconomic, financial and institutional determinants. It is found that all of these types of variables significantly explain central bank communication about financial stability and uncertainty. Moreover, central banks in most of the countries considered appear responsive to some developments in asset markets and financial conditions more generally, commodity prices, in addition to the standard determinants of central bank interest rate rules, namely output and inflation developments. Finally, central bank statements tend to reflect the view that these serve, in part, to complement changes in policy rates as well as the introduction of 'unorthodox' policies such as quantitative easing or conditional commitments on policy rates. 
In spite of these results there are several ways in which the results of this paper can be improved. For example, the content indicators are examined separately whereas, in reality, the content of central bank releases likely reflects a balance among several competing indicators. Second, some of the determinants of content may not be exogenous. Third, it is likely that the content of meetings of minutes differs from that of policy statements. Hence, a deeper investigation of the relative information content of the two types of releases is likely to be a fruitful area of investigation. All of these extensions are left for future research. Furthermore, the relatively small number of observations for some of the central banks suggests that a more meaningful empirical approach would be to estimate the hypothesized relationship in a panel setting. Finally, I did not consider whether the particular dictionary used might have influenced the results. Although DICTION relies on a dictionary of financial terms and, in this study, I have created a separate dictionary that focuses on how the language of central bank press releases might have changed since the global financial crisis, there is the possibility that neither dictionary adequately conveys the content of central bank press releases or the minutes of policy board meetings. Loughran and McDonald (2012) demonstrate that a great deal of care is needed when quantifying language in the manner done here. 
Figure 1 Central Bank Policy Rates: RBA, BoC, RBNZ, BoE, and Fed

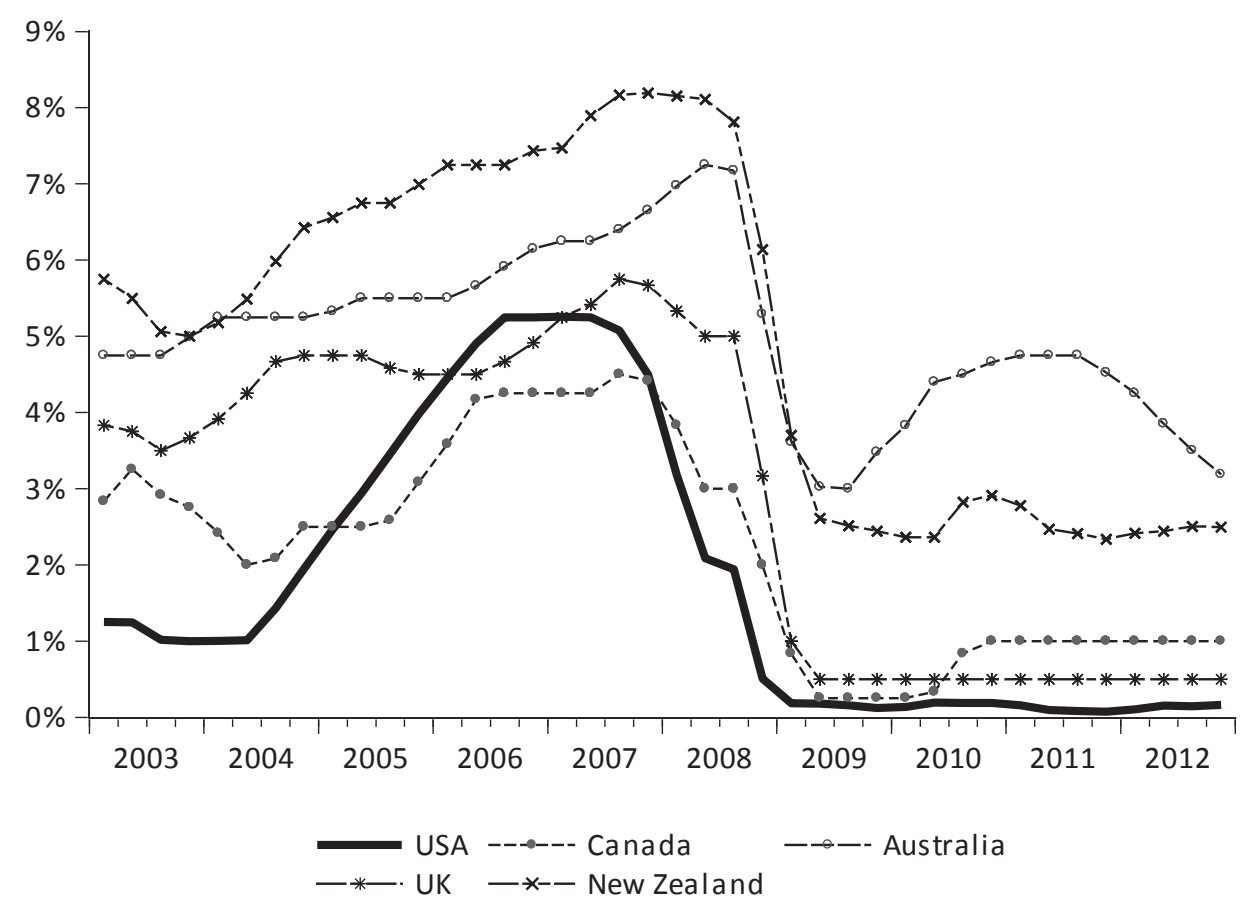

Sources: Central bank websites, International Financial Statistics CD-ROM (January 2013). For the FED the policy rate is the fed funds rate, for the BoC it is the overnight target rate, for the RBA and the RBNZ it is the cash rate, and for the Bank of England it is the bank rate. Data are monthly. 

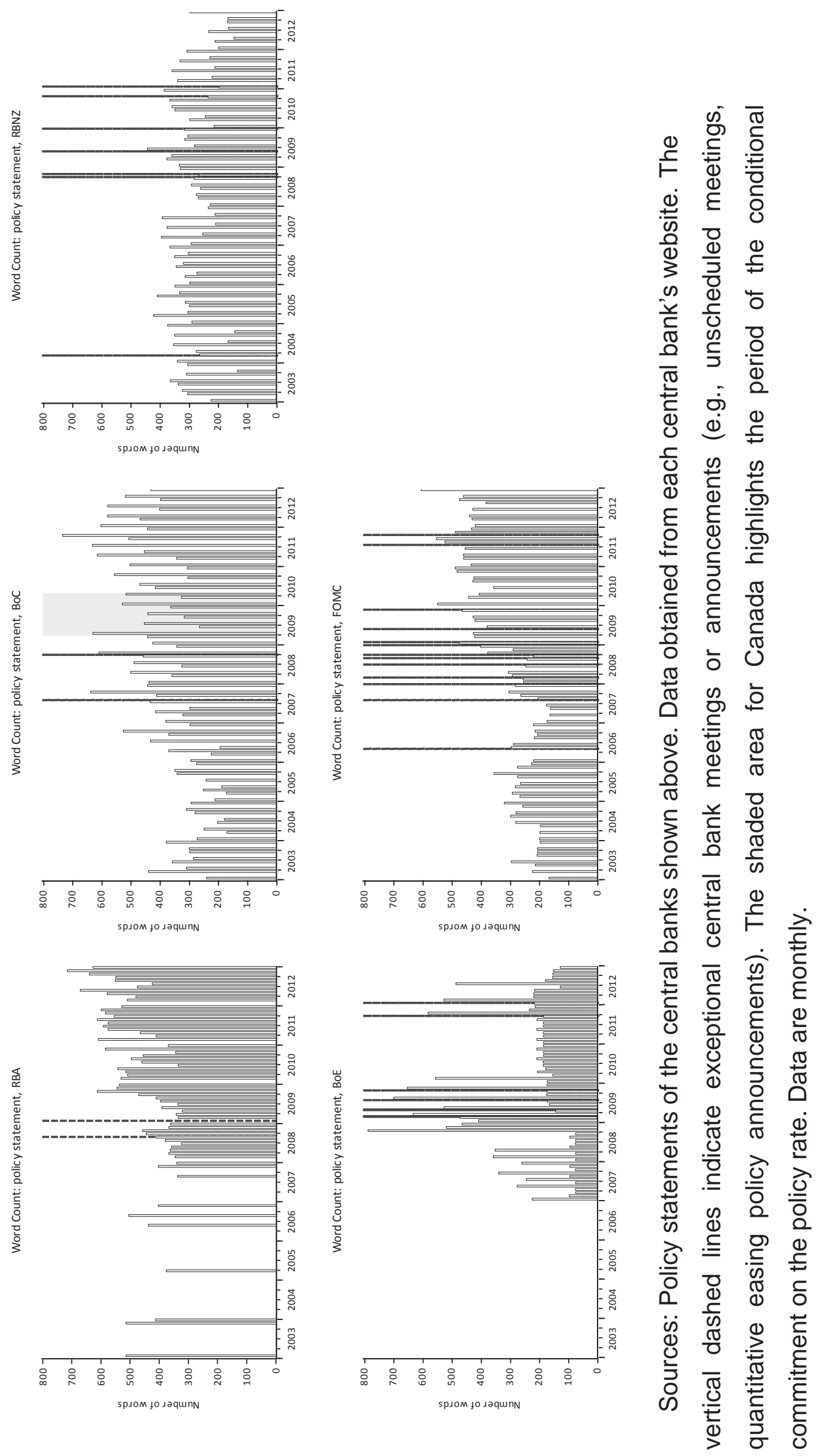
Figure 3 Word Count, Minutes of Policy Committees

Word count, minutes: RBA

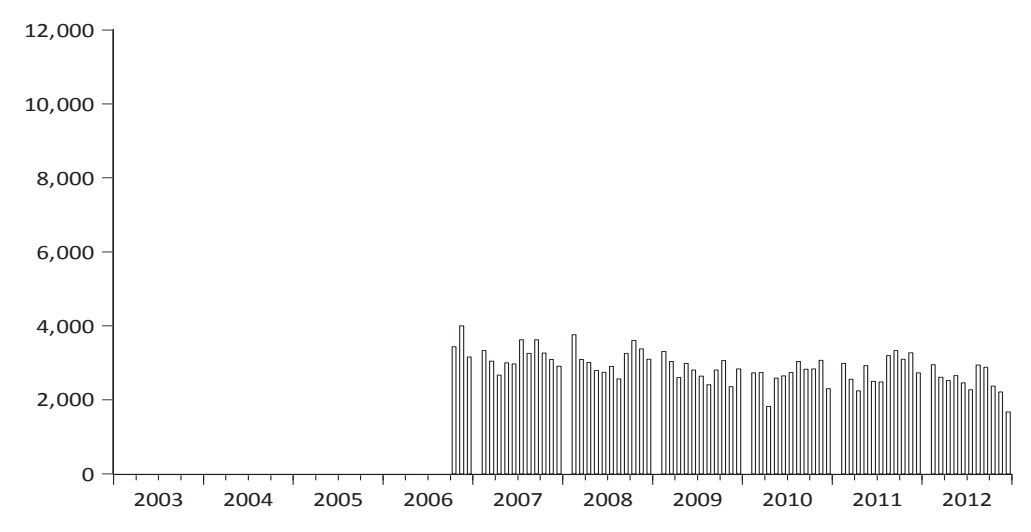

Word count, minutes: BoE

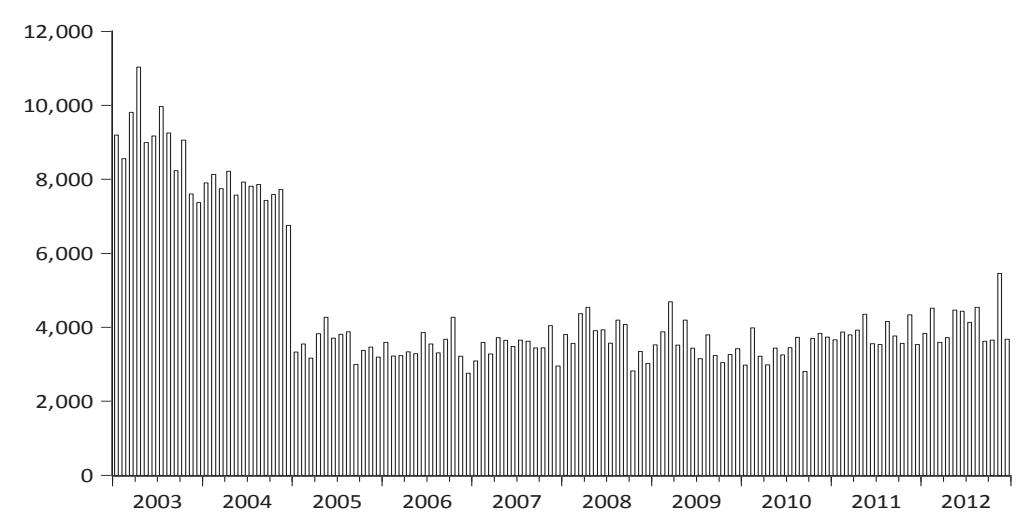

Word count, minutes: FOMC

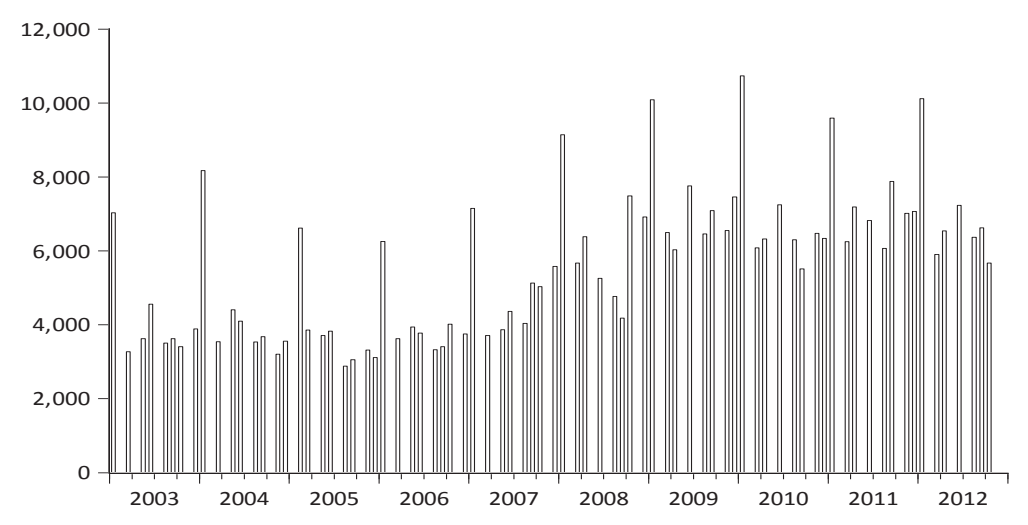

Note: See sources to Figure 3. No minutes were published by the RBA before the end of 2006. Data are monthly. 


\section{Figure 4 Word Count - Policy Rate Change Trade-Off}
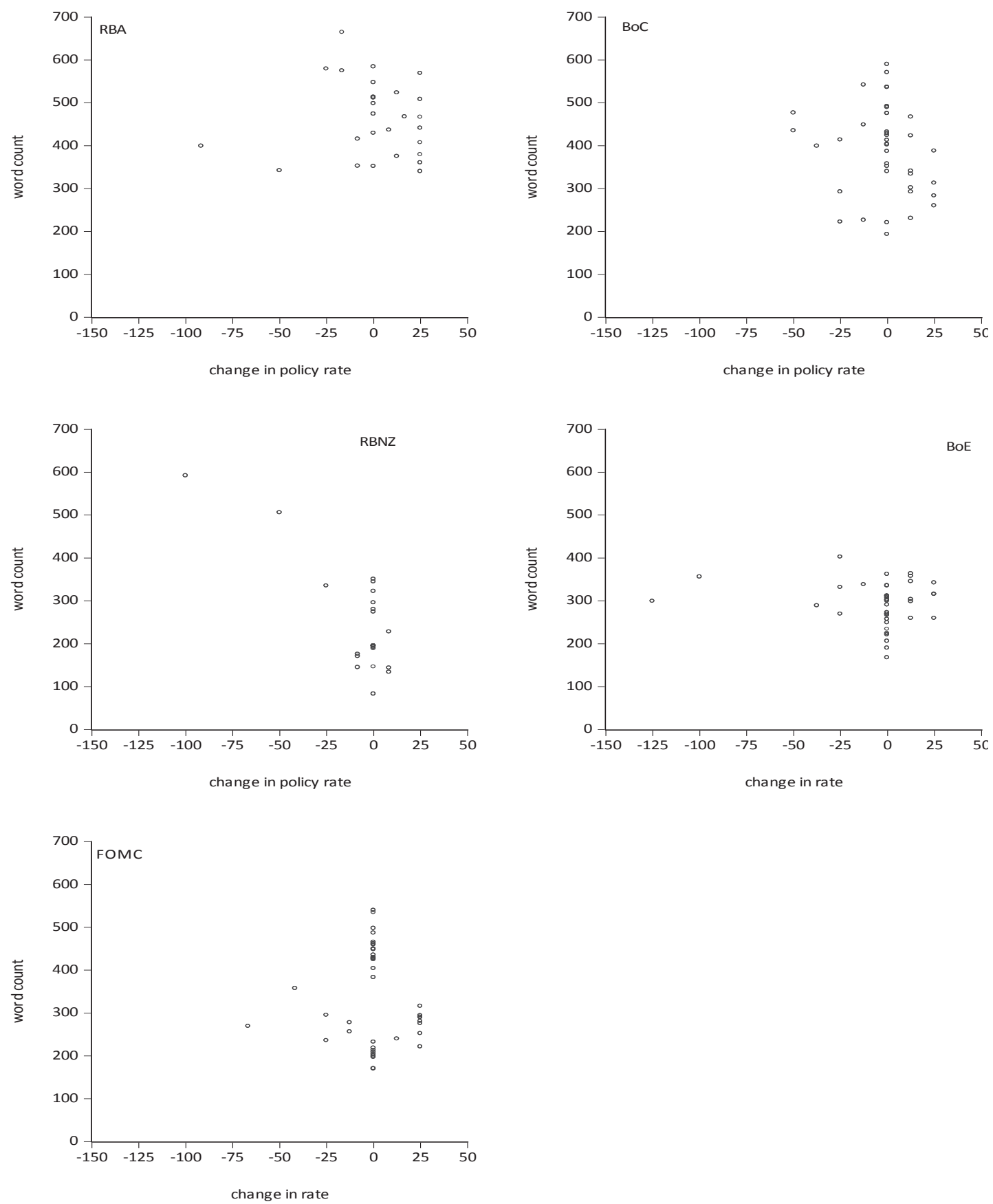

Note: Data are monthly. 


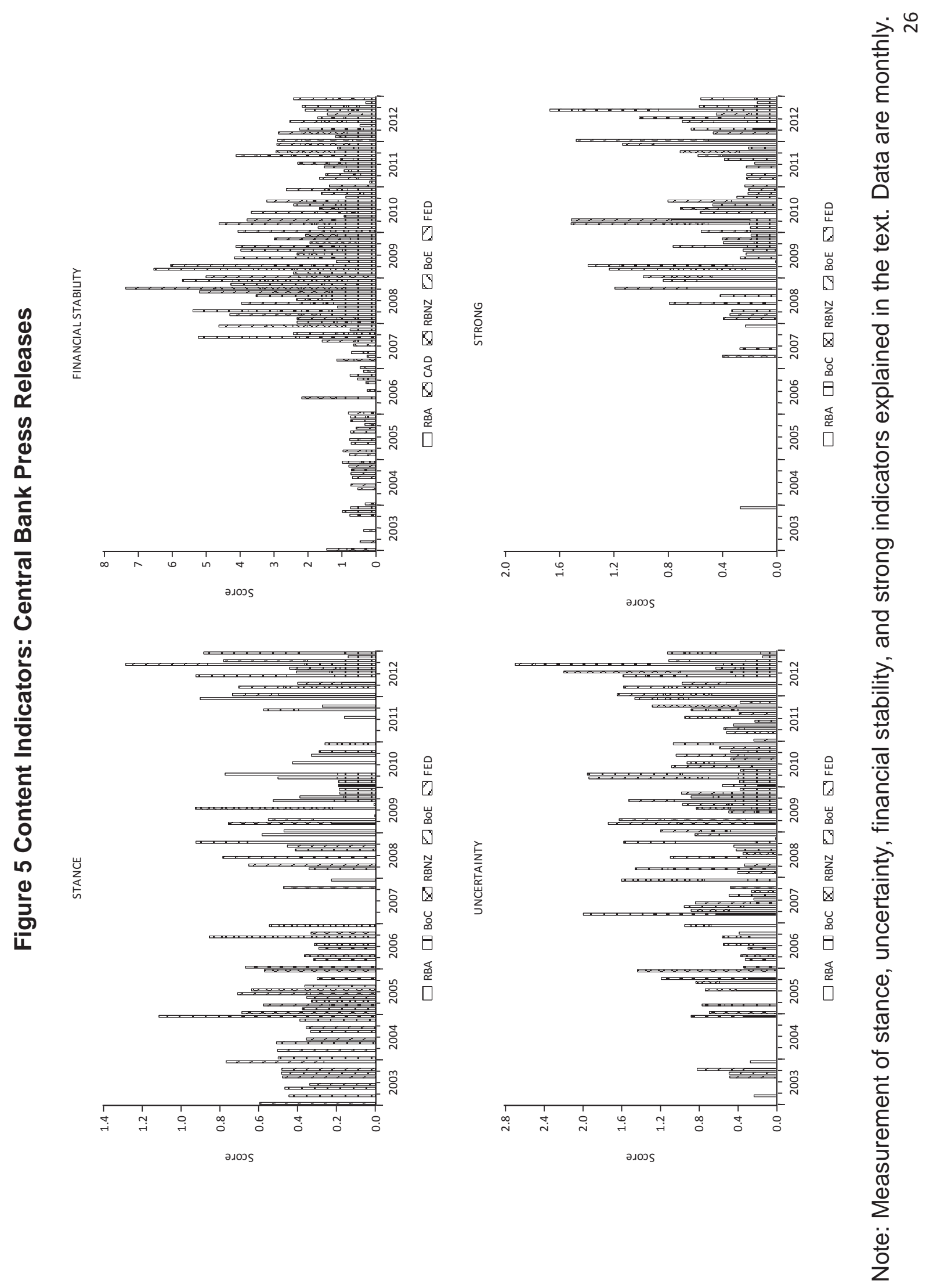


$\lesssim$
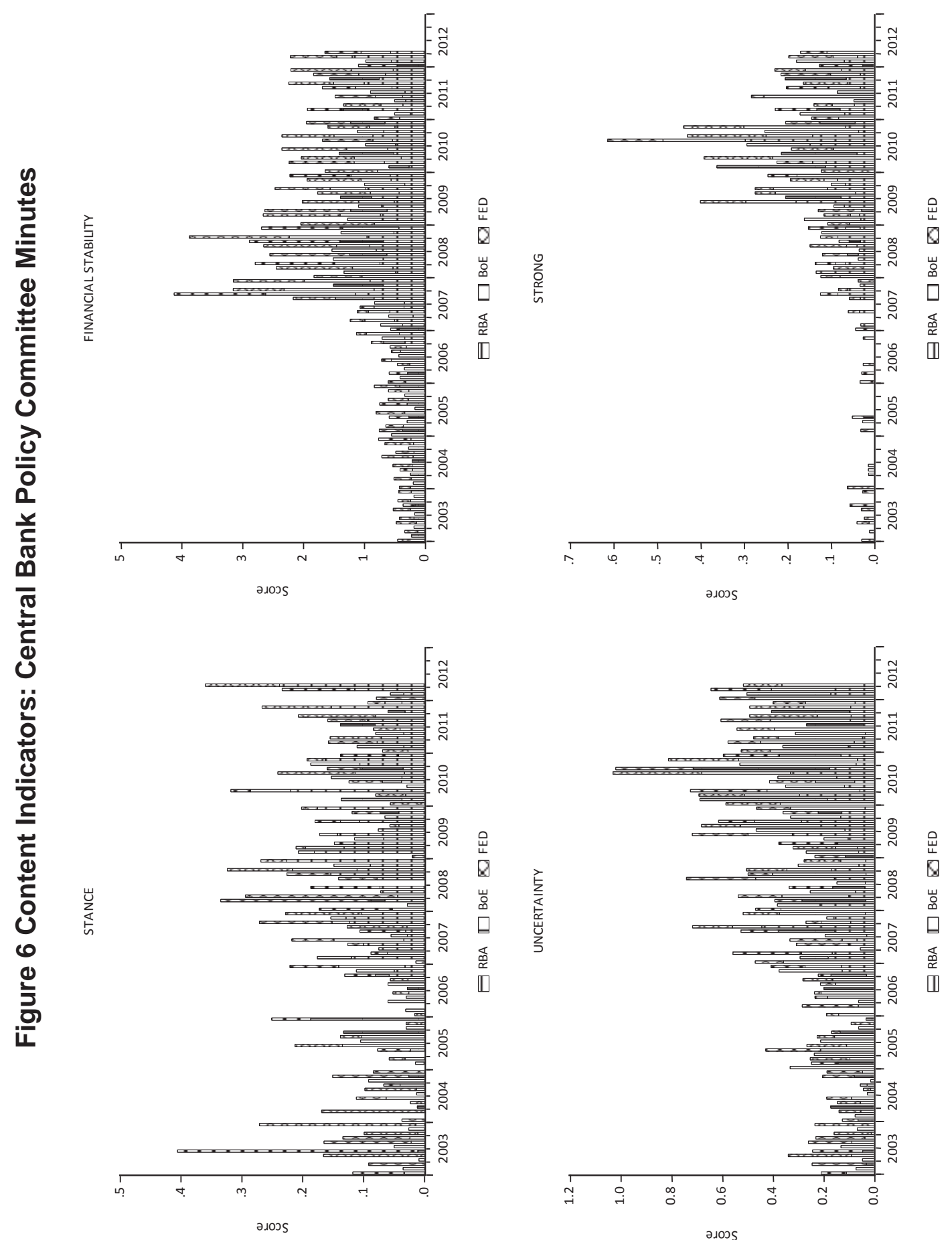

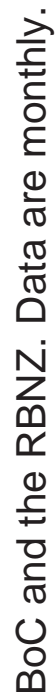

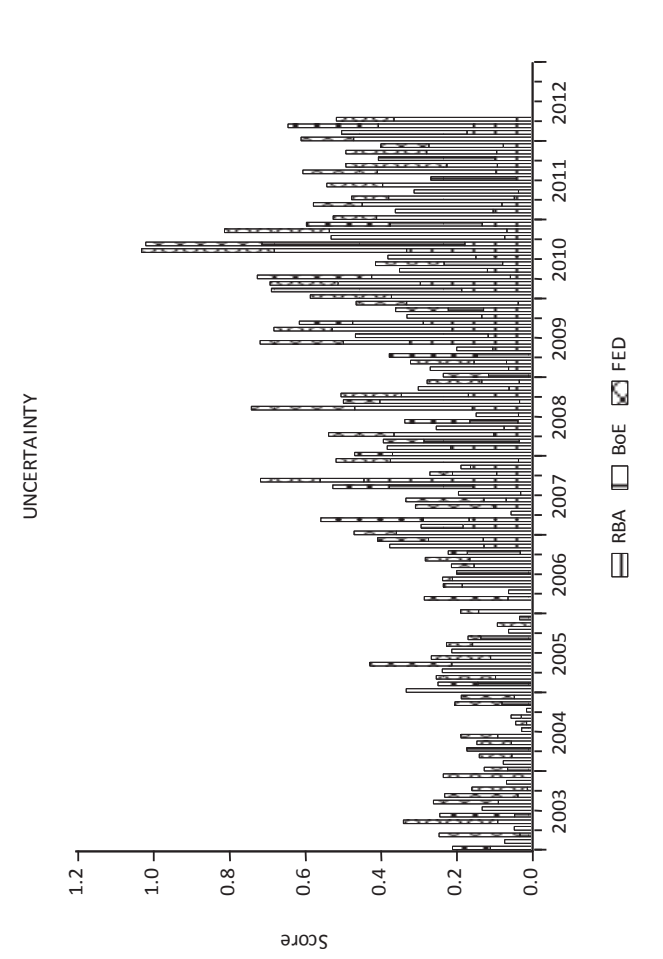

$\stackrel{9}{\rightleftharpoons}$

ล

$\frac{\bar{d}}{\frac{0}{0}}$

$\frac{0}{\sigma}$

is

․ㅗㄹ

등

Z

5

음

흐

웅

ัㅗㅡ

ఖ

迨 

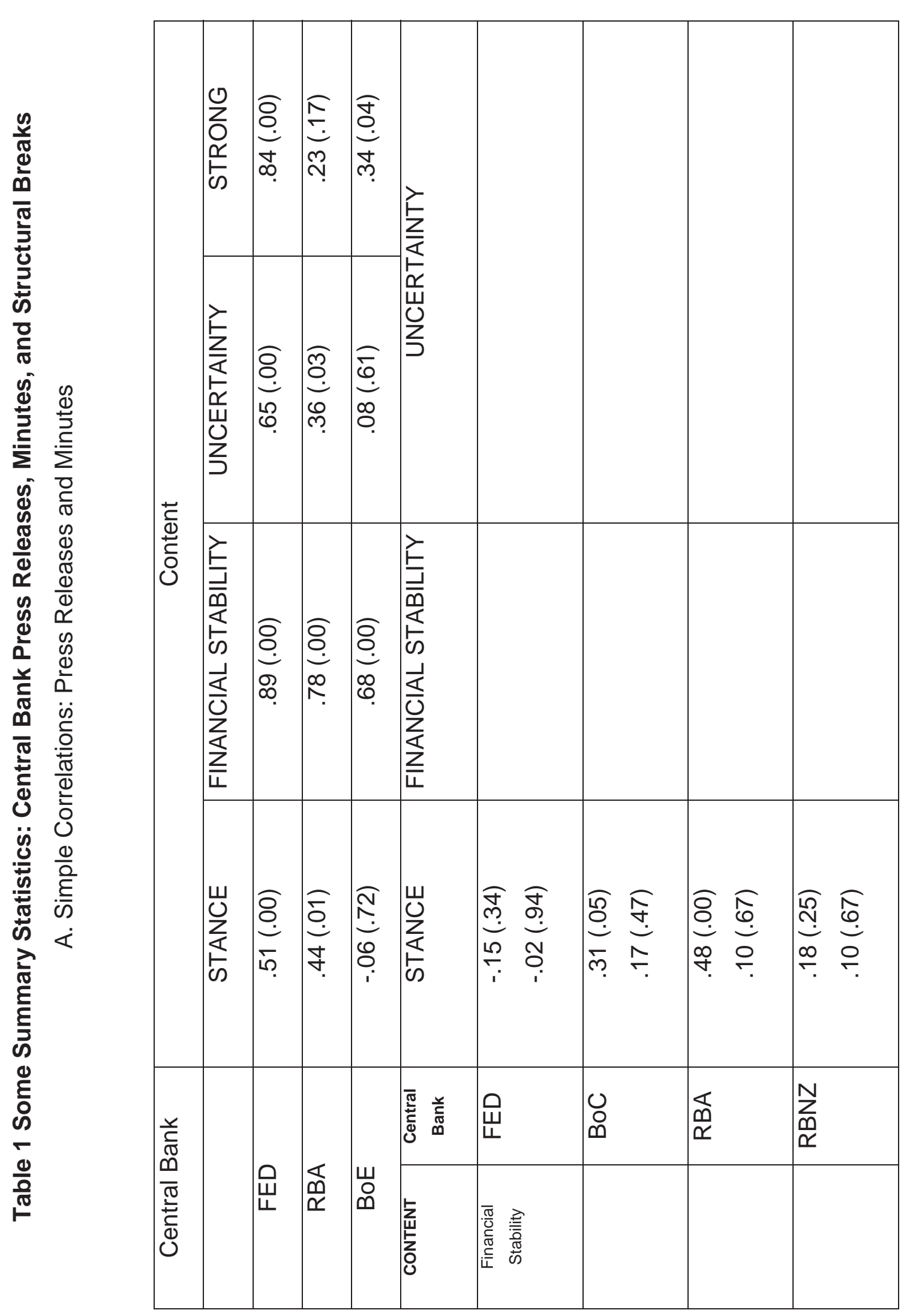

$\stackrel{\infty}{\sim}$ 


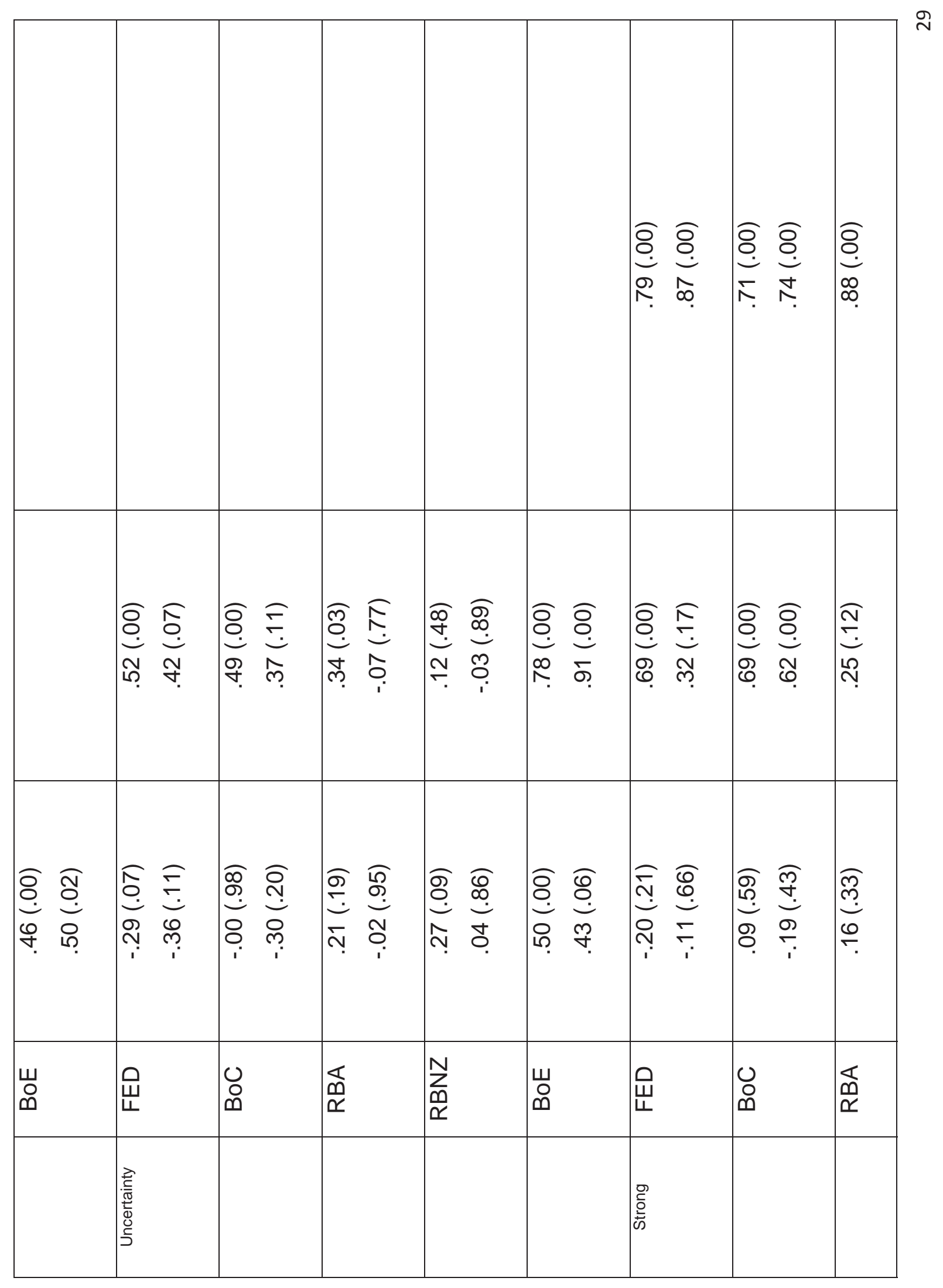




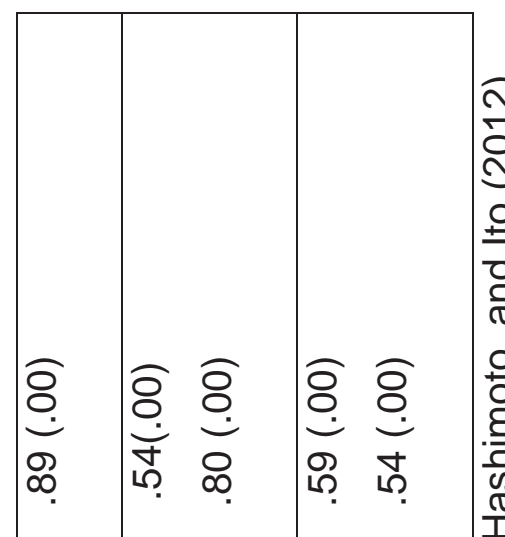

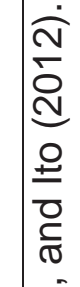

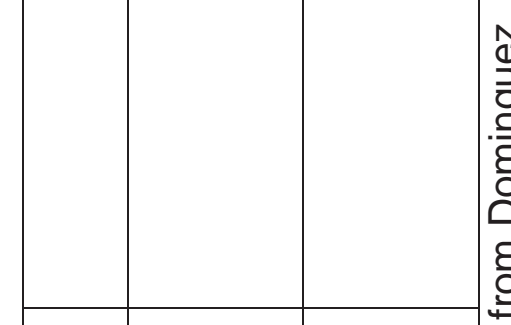

ก|

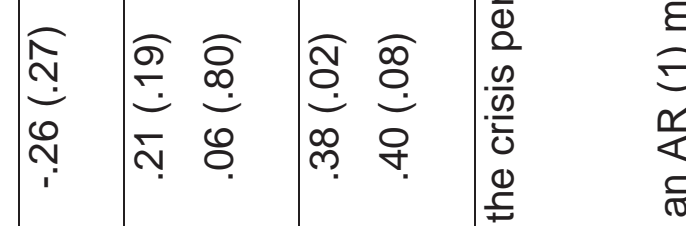

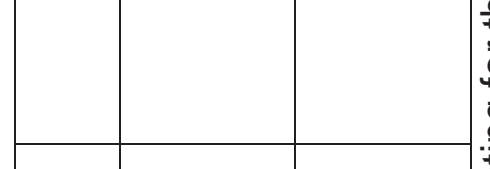

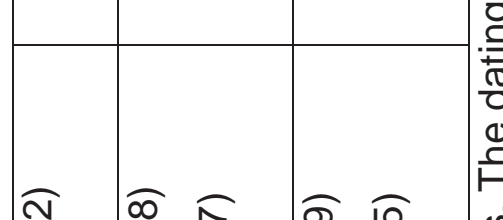

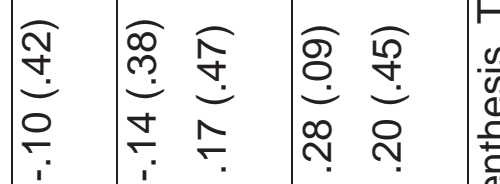

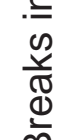

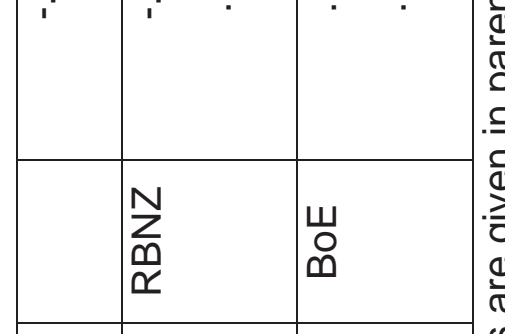

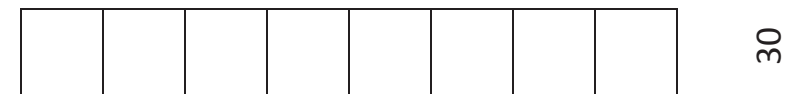

$\frac{\sqrt{8}}{\frac{8}{0}}$

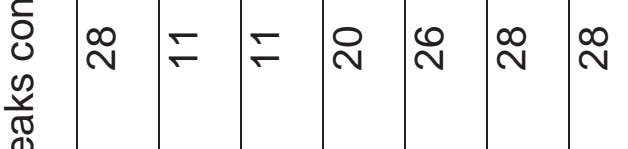

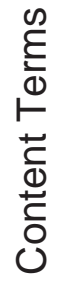

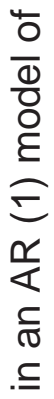

ฉิ

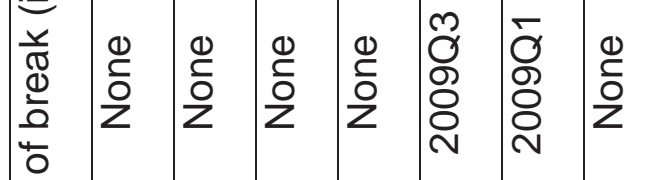

产

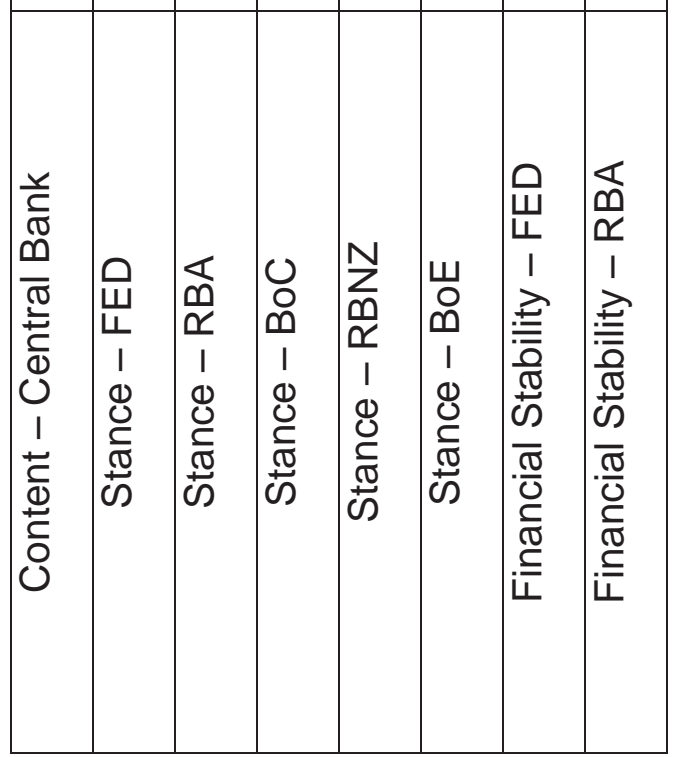




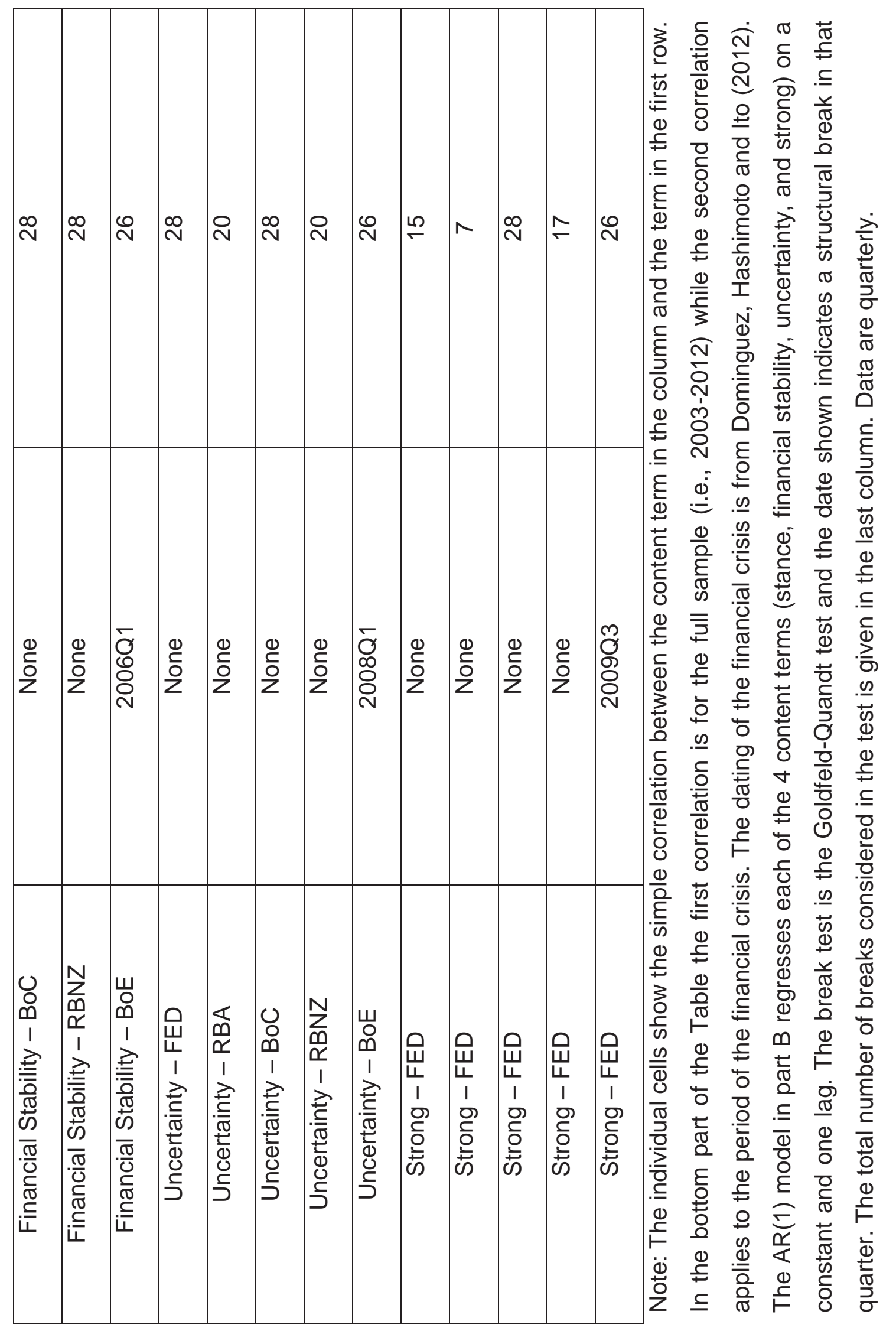




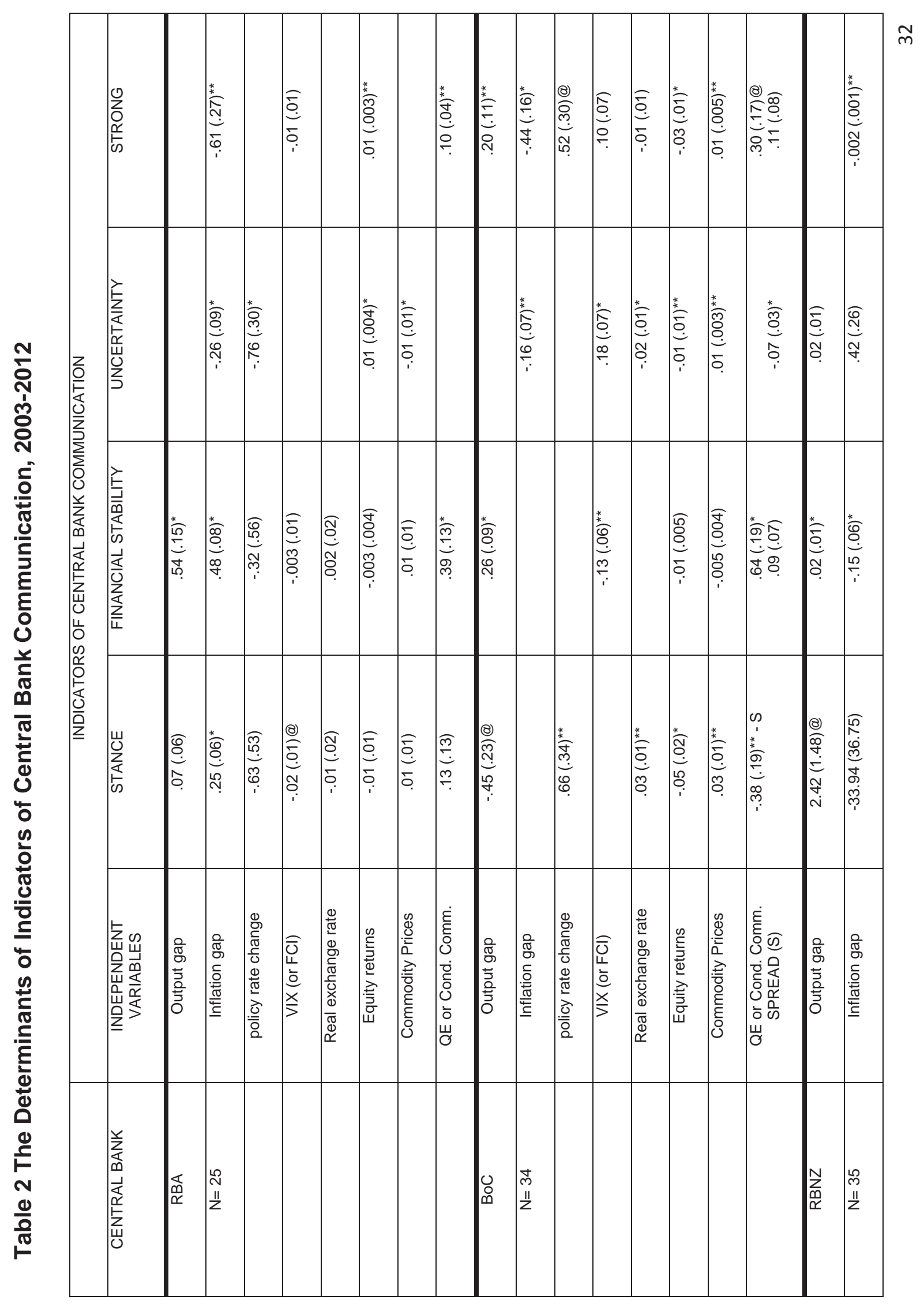




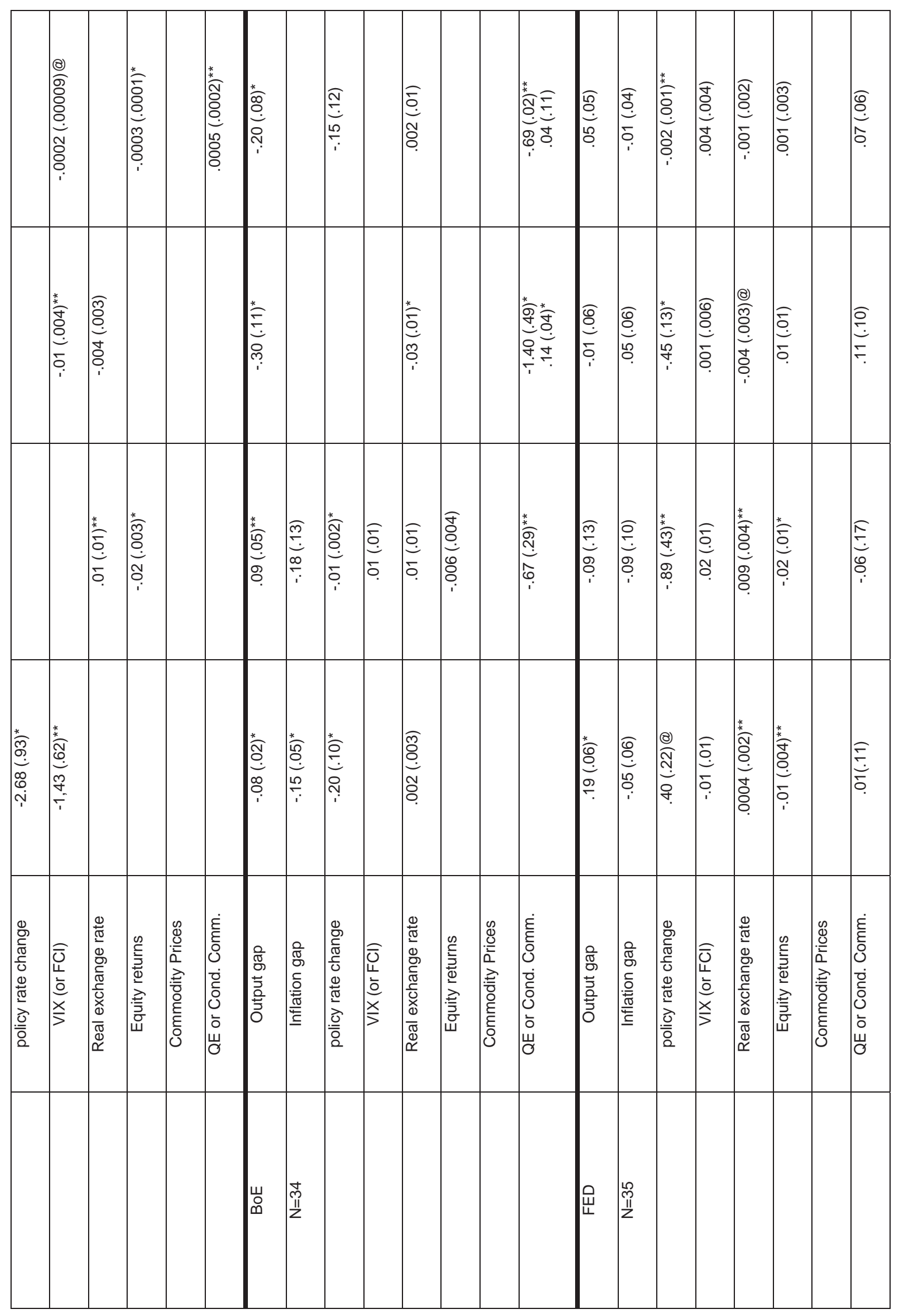




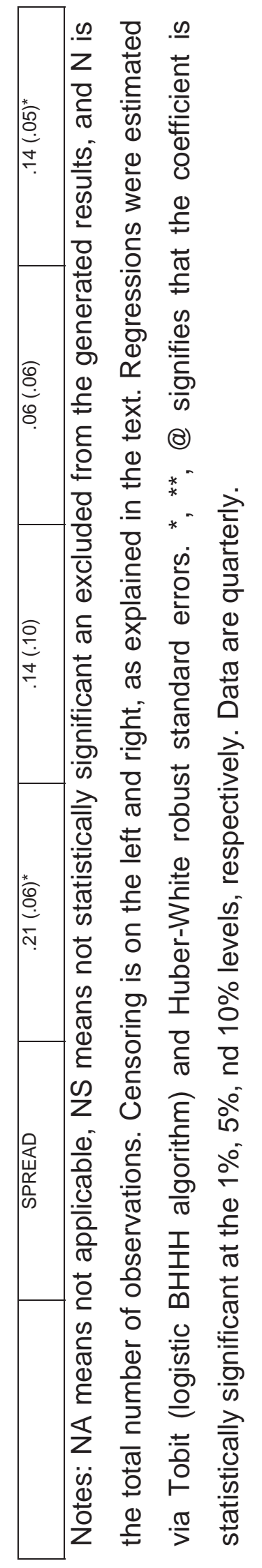


References

Berger, H., M. Ehrmann, and M. Fratzscher (2011), Monetary Policy in the Media. Journal of Money, Credit and Banking 43 (4):689-709.

Bini-Smaghi, L. (2007), "The Value of Central Bank Communication”, Brussels, 20 November, speech available from www.ecb.int.

Bligh, M., and G. Hess (2013), "Deconstructing Alan: A Quantitative Assessment of the Qualitative Aspects of Chairman Greenspan's Communication” in P.L. Slklos and J.-E. Sturm (Eds), Central Bank Communication, Decision-Making and Governance (Cambridge Mass.: MIT Press, forthcoming).

Blinder, A.S., M. Ehrmann, M. Fratzscher, J. De Haan and D.-J. Jansen (2008), "Central Bank Communication and Monetary Policy: A Survey of Theory and Evidence", Journal of Economic Literature 46 (December): 910-45.

Born. B., M. Ehrmann, and M. Fratzscher (2013), "Central Bank Communication on Financial Stability", European Central Bank working paper, Economic Journal (forthcoming).

Born, B., M. Ehrmann, and M. Fratzscher (2010), "Macroprudential Policy and Central Bank Communication", European Central Bank, May.

Bulír, A., M. Číhák, and D.-J. Jansen (2012), "Clarity About Central Bank Communication About Inflation", IMF working paper 12/9, January.

Dale, S., A. Orphanides, and P. Österholm (2011), "Imperfect Central Bank Communication: Information Versus Distraction", International Journal of Central Banking 7(2): 1-39.

Demers, E., and J. Yu (2013), "Linguistic Clarity in Managerial Announcements", in this volume. 
Dominguez, K., Y. Hashimoto, and T. Ito (2012), "International Reserves and the Global Financial Crisis", Journal of International Economics 88 (November): 388406.

Ehrmann, M., and M. Fratzscher (2009), Explaining Monetary Policy in Press Conferences. International Journal of Central Banking 5 (2):42-84.

Ehrmann, M., and M. Fratzscher (2007), "Communication and Decision-Making by Central Bank Committees: Different Strategies, Same Effectiveness?", Journal of Money, Credit and Banking 39 (2-3): 509-541.

Eusepi, S., and B. Preston (2010), "Central Bank Communication and Expectations Stabilization", American Economic Journal: Macroeconomics 2(July): 235-71.

Loughran, T. and McDonald (2011), "When is a Liability Not a Liability? Textual Analysis Dictionaries, and 10-Ks", Journal of Finance 66 (1): 35-65.

Lucca, D. O., and F. Trebbi (2009), Measuring Central Bank Communication: An Automated Approach with Application to FOMC Statements. NBER Working Paper w15367.

Morris, S., and H.S. Shin (2002), "Social Value of Public Information", American Economic Review 92 (December): 1521-1534.

Siklos, P.L. (2012), "Communication for Multi-Taskers: Perspectives on Dealing with Both Monetary Policy and Financial Stability", working paper, Wilfrid Laurier University.

Tudor, C. and C. Vega (2013), "A Literature Review of the Use of Automated Textual Analsysis Algorithms in Economics and Finance", unpublished.

Woodford, M. (2005), "Central Bank Communication and Policy Effectiveness", in The Greenspan Era: Lessons for the Future (Federal Reserve Bank of Kansas City: Kansas City). 
Yellen, J. (2012), "Revolution and Evolution in Central Bank Communications", at Haas School of Business, 13 November, speech available from http://www.federalreserve.gov/newsevents/speech/2012speech.htm. 